\title{
Social aspects of the Earth sciences Interview with Prof. Franco Ferrarotti
}

\author{
Silvia Peppoloni
}

\author{
Article history \\ Received March 2, 2012; accepted March 10, 2012. \\ Subject classification: \\ Geoethics, Earth sciences, Society, Scientific information, Geological hazard.
}

Franco Ferrarotti, Professor emeritus at 'La Sapienza' University of Rome; since winning the first Chair in this discipline in Italy in 1961, he has been considered the Father of Italian Sociology. An independent Member of Italian Parliament in the third government (1958-1963), a member of the New York Academy of Sciences, and a 'visiting Professor' at many universities in Europe, North America, Russia, Japan and Latin America. Franco Ferrarotti has taught and still teaches in Europe and America, and he has received many awards throughout his career.

In this interview, he talks about the social aspects and consequences of Earth sciences studies.

\section{Silvia Peppoloni (S.P.)}

Good morning Prof. Ferrarotti. As one of the most important sociologists in the world, you can really help us to reflect on some essential points that must accompany our activities as geologists. As geologists, we study the Earth, and the natural phenomena that take place on it, and we try to understand the causes, and to mitigate their negative effects. What are the social consequences of geological practice and research?

\section{Franco Ferrarotti (F.F.)}

At least for the time being, they are practically irrelevant. As almost all scientists in Italy in particular, geologists are not heard. At the present time, Italy is still culturally midway between the world of yesterday's carelessness, the period of the great pre-scientific traditions, and the technologized and rationalized world. Scientific evaluation, which should give us the exact coordinates of where we are and suggest what has to be done to reduce the risks, is irrelevant at the moment. Science is viewed as entertainment, but it does not involve us, because the prevailing mentality both in policy makers and in ordinary people translates and reduces the political problems into literary perorations, transforms ethical problems into esthetic attitudes. This is the culture of 'beautiful singing': geologists say useful things, but unfortunately they do not sing.

S.P.

What can we do as geologists to change this state of affairs?

F.F.

Geologists can do a lot. It is necessary to have greater moderation in judgments. In schools, there must be more space for scientific subjects. The risk we run is to move from a miracle-working and superstitious mentality to an attitude that believes that science can solve everything. This is wrong: science can have a decisive social impact to the extent that it is aware of its limitations. There are human problems, such as love, justice and death, that cannot be solved by science; however, science can help us. In a country such as Italy especially, which is geologically ruined, from Sicily to Trentino, geology can achieve a lot.

This does not happen though, because of the Italian mentality, which is still deeply conservative, miracle-working, and devoted to chance and luck.

\section{S.P. \\ What role do the media have in this situation?}

F.F.

The media, as television, the internet, YouTube, and much more, are important, but they are ethically indifferent: they theatricalize everything; everything becomes entertainment, and so an escape from the real problems. Instead, specific problems require the intervention of science. Science must make the transition from common opinion to established truths. It is generally believed that problems can be solved by using the media properly. This is a commonly held illusion. This is because there is something intrinsic to the media, which does not help the ra- 
tional interpretation of the situation. The media crush everything into the present time, and eliminate the memory. Moreover, media do not mediate. For geologists, the memory is essential, because geological phenomena must be studied in a temporal dimension. The media, with their foolish 'presentism', cancel out the dimension of time.

\section{S.P.}

Speaking of 'memory', we were all amazed to learn that during the disaster in Sumatra, there were some indigenous people who recognized the precursors of the tsunami and saved themselves from the waves. Thinking about the Italian situation, about our villages inured to living together with the fragility of their territory: how important is it to maintain a collective memory of the hazards, of the disasters, that have occurred in our territory?

\section{F.F.}

Collective memory is fundamental, but we are losing it. Italy has become industrialized very quickly, in a single generation, and today we live in an industrial country, but we do not have an industrial culture. We have lost the wisdom of our ancestors, but we have not yet assimilated the scientific values. The media work against the memory. Also thinking about history, when history is treated by the media, you lose the direct relationship with the ancient existential memory; on the contrary, our ancestors had it. On television, memory looks like an archeological find, which is separated from us: it entertains us, but it does not involve us. And still, without memory, we are nothing; without memory, there is gratuitousness, fatuousness, irresponsibility, and in the end, pure madness. Man is only what he remembers he has been. Memories are fundamental to understand where we came from, to understand our present situation, and to build a project for our future.

As Giustino Fortunato, an expert in the problems of southern Italy, wrote, "Italy is a completely ruined territory hanging over the sea". And then the question can be raised: where are the geologists? They should be in the front rows, they should be worshiped as 'gurus'. Instead, they live in their little corner, without disturbing anyone. They should yell: "We are in danger! The Italian territory is one of the most seismic of our entire Planet. At least, let us try to identify the real terms of the situation!"

In Italy, geologists are in an almost worse condition than sociologists. We are in the middle of enormous social problems and solutions are not found; they are not even looked for. We are faced with a territory that is crumbling, with houses that move, with hills that slide down, and geologists in Italy are simply not there. Their silence is deafening. From my point of view, this is the situation, and surely it is not positive nor adequate to solve the problems we are bound to face in the near future.

\section{S.P.}

Thank you, Professor, for the strong impulse that you have given us for changing this state of affairs. We will certainly bear your advice in mind.
Corresponding author: Silvia Peppoloni, Istituto Nazionale di Geofisica e Vulcanologia, Rome, Italy; email: silvia.peppoloni@ingv.it.

(C) 2012 by the Istituto Nazionale di Geofisica e Vulcanologia. All rights reserved. 